\title{
Differences in Diabetes Care With and Without Certification as a Medical Home
}

Leif I. Solberg, $M D^{1}$

Caroline Carlin, $P b D^{2}$

Kevin A. Peterson, MD, MPH ${ }^{2}$

Milton Eder, $P b D^{2}$

'HealthPartners Institute, Minneapolis, Minnesota

${ }^{2}$ University of Minnesota, Minneapolis, Minnesota
Conflicts of interest: authors report none.

\section{CORRESPONDING AUTHOR}

Leif I. Solberg, MD

HealthPartners Institute

PO Box 1524, MS\#23301A

Minneapolis, MN 55440-1524

Leif.I.Solberg@HealthPartners.com

\begin{abstract}
PURPOSE The purpose of this study was to assess whether primary care practices certified as medical homes differ in having the practice systems required for that designation and in attaining favorable outcomes for their patients with diabetes, and whether those systems are associated with better diabetes outcomes.
\end{abstract}

METHODS We undertook a cross-sectional observational study, Understanding Infrastructure Transformation Effects on Diabetes (UNITED), of 586 Minnesota adult primary care practices, comparing those that were certified vs uncertified as medical homes in 2017, with analyses supplemented by previously published studies of these practices. We collected survey information about the presence of medical home practice systems for diabetes care and obtained 6 standardized measures of diabetes care collected yearly from all Minnesota practices.

RESULTS Of 416 practices completing questionnaires (71\% of all practices, $92 \%$ of participating practices), 394 had data on diabetes care measures. Uncertified practices (39\%) were more likely than certified practices to be rural, but their patient populations were similar. Certified practices had more medical home practice systems $(79.2 \%$ vs $74.9 \%, P=.01)$ and were more likely to meet a composite measure of optimal diabetes care (46.8\% vs $43.2 \%, P<.001)$. A 1 -SD increase in presence of practice systems was associated with a $1.4 \%$ higher probability of meeting that measure $(P<.001)$.

CONCLUSIONS Practices certified as medical homes have more practice systems and higher performance on diabetes care than uncertified practices, but there is extensive overlap, and any differences may reflect self-selection for certification.

Ann Fam Med 2020;18:66-72. https://doi.org/10.1370/afm.2492.

\section{INTRODUCTION}

I $\mathrm{n}$ the last 10 years, the concept of a medical home for patients, a patientcentered medical home $(\mathrm{PCMH})$, has resurfaced from its origins in pediatrics in 1967., ${ }^{1,2}$ The idea has received enormous interest in the United States as a potential vehicle for transforming the quality, experience, and costs of medical care. It has even led to creation of a large collaborative, the Patient-Centered Primary Care Collaborative, having more than 1,000 participating organizations, ${ }^{3,4}$ to promote its spread. There have been many demonstration projects and studies, and there are a variety of national and state processes to recognize or certify practices as $\mathrm{PCMHs}_{i}$ however, the definitions and criteria for what constitutes a PCMH vary widely, and most studies lack comparison groups and suffer from volunteer bias. ${ }^{5}$ There are thus still many unanswered questions, including the following ${ }^{6,7}:$ how do practice systems and outcomes in a PCMH-recognized practice differ from those in others without that designation? Is there a continuum of characteristics and performance among practices that are or are not PCMH recognized, or is there a clear distinction between these groups? And are these practice systems associated with diabetes care quality and outcomes?

The most widely used recognition for what constitutes a PCMH is the process established by the National Committee for Quality Assurance (NCQA) ${ }^{8-11}$ Minnesota was one of the first states to implement its own vol- 
untary certification process for primary care practices in 2010, based on demonstration that a practice met 5 standards (criteria) after thorough review ${ }^{12}$ : (1) continuous access and communications with patients and family; (2) an electronically searchable registry to identify care gaps and manage services, (3) care coordination for patient- and family-centered care ${ }_{i}(4)$ care plans that involve patients with chronic or complex conditions; and (5) continuous improvement in patient satisfaction, outcomes, and cost-effectiveness.

These standards must be thoroughly described in an application and demonstrated to be in routine use during required site visits, both initially and at the 3 -year recertification point. They are very similar to features the Agency for Healthcare Research and Quality has identified as the key functional attributes of a PCMH: comprehensive care, patient-centered care, coordinated care, accessible services, and quality and safety. ${ }^{13}$ As an incentive to apply for certification, Minnesota also developed a supplemental payment to certified practices for their Medicaid patients that depended on the complexity of their medical conditions. By late 2017,61\% of the 586 primary care practices in the state and border communities had been certified as a health care home $(\mathrm{HCH})$, Minnesota's term for the PCMH.

The certification standards above require practice processes and systems that can be measured and reviewed triennially. Because all practices in Minnesota are also required to submit standardized data for public reporting on a variety of quality, satisfaction, and cost measures, these data provided us with an opportunity to test whether those practices that were adopters of $\mathrm{HCH}$ certification differed in systems and outcomes from uncertified practices. By exploring the differences between these 2 cohorts for adults with diabetes, we hoped to obtain answers to the 3 questions above.

\section{METHODS}

\section{Practice Recruitment}

We undertook a cross-sectional observational study, Understanding Infrastructure Transformation Effects on Diabetes (UNITED), of 586 primary care practices, 95\% of them contained within 101 medical groups of varying size and type, that participated in Minnesota's 2017 public reporting on quality of care for adult patients with diabetes. Of these, 355 (61\%) were certified as HCHs as of July 2017. Practices that were part of multisite medical groups were recruited through their medical directors.

Recruitment involved first sending a letter by Federal Express, followed in 1 week by an e-mail to the medical leader describing the study and its requirements and benefits for them. Participation required identifica- tion of the leaders at each practice site and encouragement for their completion of a single questionnaire in 2017. The only benefits for participants were provision of comparative information about their care processes and our findings on successful strategies for improving performance measures. This e-mail was followed by a telephone call from 1 of 2 physician authors (L.I.S. or K.A.P.) who are widely known to the state's physicians. Follow-up calls, e-mails, or both were used until leaders verbally consented or declined, or we concluded that we would not be able to obtain an answer.

\section{Survey Data Collection}

A leader of each participating practice was asked to complete an 81-question questionnaire asking about the presence of various practice systems to support high-quality care for patients with chronic conditions. The questionnaire was first created and tested for reliability by the National Committee for Quality Assurance as a way of assessing the presence of various features of the Chronic Care Model. ${ }^{14}$ It has been widely used in research and has been demonstrated to be associated with quality of care for patients with diabetes or depression, and with health care use and costs for patients with diabetes. ${ }^{15-17}$

To create summary measures of practice systems in place, each question was scored as 0 (no such system was present) or 1 (a system was present). We limited our analysis to the 32 questions addressing diabetes care in the 5 domains required for certification in Minnesota (Table 1). Both the overall score and scores for each domain were calculated as a percentage of the total possible score, with equal weight for each question.

\section{Outcomes Data Collection}

Diabetes performance measures for each practice were obtained from MN Community Measurement (MNCM), the region's nonprofit organization for collecting and publicly reporting standardized performance measures for medical care ${ }^{18}$ For diabetes, these measures include the proportions of diabetic patients having hemoglobin $\mathrm{A}_{1 \mathrm{c}}$ control, having blood pressure control, using statins, using prophylactic aspirin, and not smoking, as well as a composite all-or-none measure of the proportion of patients meeting all 5 measures, indicating optimal diabetes care. Practices use direct data submission procedures to provide these patientlevel measures for their diabetic population to MNCM as a part of the Minnesota Department of Health Statewide Quality Reporting and Measurement System.

\section{Analysis}

We first computed summary statistics describing the practices and their diabetic patient populations by 
certification status, as well as their mean prevalence of practice systems and diabetes care measures. To account for differences in patient and practice characteristics, we also conducted multivariate analyses

\section{Table 1. Practice Systems Questions for HCH Certification That} Address Diabetes Care, in 5 Domains

Access: continuous access and communications with patients and family

1. "Advanced access" or "open access" visits (scheduling that encourages your office staff to offer same-day appointments to virtually all patients who want to be seen)

2. Scheduling system to encourage patients to see their personal physician

3. Follow-up when diabetes patients have missed important appointments

4. System to identify and remind patients with diabetes who are due for a follow-up visit

5. System to identify and remind patients with diabetes who are due for testing

6. System to identify and remind patients with diabetes who are due for a prescription renewal

7. System to identify and notify patients who are due for age-appropriate preventive services

8. Routine use of secure e-mail to support self-management for patients and their families

9. Routine use of an interactive website to support self-management for patients and their families

10. Routine use and data exchange with patients who have access to their own electronic health record

Registry: an electronically searchable registry to identify care gaps and manage services

1. A registry for diabetes (list of patients along with associated data)

2. Guideline-based reminders for services the diabetic patient should receive that appear when seeing the patient

3. Checklists of tests or interventions that are needed for prevention or monitoring of diabetes

4. System to provide alerts about important abnormal test results to the doctors at the time they are received

Coordination of care: care coordination for patient- and family-centered care

1. Nurse managers to coordinate care for patients with especially complicated conditions

2. System for tracking laboratory or radiology tests until results are available to the clinician

3. System to track critical referrals until the consultation report returns to the practice

4. Designated primary care teams, defined as a physician and other staff that collaborate in the care of a defined group of patients

5. Previsit planning routinely provided to patients with diabetes by someone other than a physician, PA, or NP

6. After-visit follow-up routinely provided to patients with diabetes by someone other than a physician, PA, or NP

7. Provide or refer patient with diabetes to formal support programs to assist in self-management

8. System to promptly learn when one of your patients has been discharged from a hospital

9. System in place to manage recently discharged patients

Care plans: care plans that involve patients with chronic or complex conditions

1. Routine development of individualized self-management plans with goals for patients with diabetes

2. Routine provision and review of self-monitoring instructions for patients with diabetes

3. Provide written materials that explain to the patient the recommended medical care guidelines for diabetes

4. Systems to encourage diabetes patient self-management

5. A systematic process to conduct shared decision making with patients

6. Develop care plans with patients to manage care for diabetes

Quality improvement: continuous improvement in patient satisfaction, outcomes, cost-effectiveness

1. A formal process for measuring performance for individual physicians or for the practice site

2. Provision of data to individual physicians on the quality of their care for patients with specific chronic conditions

3. Conduct or participate in formal quality improvement activities

$\mathrm{HCH}=$ health care home; $\mathrm{NP}=$ nurse practitioner; $\mathrm{PA}=$ physician assistant.

Note: For each system, practice leaders were asked whether their practice had any such system in place. tice controls included size of the clinic's medical group (large hospital-affiliated organization, small/medium-sized organization, single site), whether the practice was a Federally Qualified Health Center (FQHC), and location of the practice (urban, large rural town, small rural town, isolated rural town). Location was defined by practice ZIP code mapped to Rural-Urban Commuting Area codes (http://depts.washington. edu/uwruca). Patient controls included patient age, sex, record of a diagnosis of ischemic vascular disease, record of diagnosed depression, presence of type 1 diabetes, and insurance type (commercial, Medicare, Medicaid, dual Medicare-Medicaid, self-pay/uninsured). In addition, we mapped patient ZIP code to the American Community Survey ${ }^{19}$ to pick up measures of the income and education, wealth, and racial composition within the patient's neighborhood.

The prevalence of practice systems, in total and by domain, was modeled at the practice level using linear regression with practice control variables. The probability of meeting the overall optimal diabetes care measure, and the probability of meeting each of its 5 components individually, was modeled at the patient level using a logit regression with patient and practice control variables. The practice survey data were cross-sectional (from 2017 only). Practice certification status did not control for volunteer bias, so those practices that were already providing better diabetes care may have been more likely to pursue $\mathrm{HCH}$ certification. For this reason, we estimated patient- 
level optimal diabetes care regression values including practice-level random effects to capture unobserved characteristics of the practices.

\section{RESULTS}

Of the 586 primary care practices providing care for adults with diabetes in Minnesota we targeted, 451 (77\%) agreed to participate in the study. With diligent follow-up, we obtained completed questionnaires from 416 of these practices, for a $92 \%$ completion rate among participating practices and a $71 \%$ completion rate among the original 586 practices targeted.

Comparison of practices responding to the survey with nonresponding practices demonstrated that the former were more likely to be in large vertically integrated systems $(74 \%$ vs $63 \%, P<.001)$ and to be located in urban settings ( $66 \%$ vs $43 \%, P<.001$ ). Responding practices were also more likely to be $\mathrm{HCH}$ certified ( $64 \%$ vs $53 \%, P<.001)$ and to have patients meeting the optimal diabetes care measure ( $46 \%$ vs $43 \%, P<.001$ ). Our use of multivariate regression analyses, however, should have normalized our results for observable differences between respondents and nonrespondents.

Among the 394 practices with both practice system data and performance measures for diabetes care, 258 (66\%) were certified as HCHs whereas 136 (34\%) were still uncertified. Characteristics of these practices by certification status are shown in Table 2. Certified practices were much more likely to be located in urban areas, but were no more likely to be independent or Federally Qualified Health Centers. Patient populations differed slightly by practice certification status, with small differences being statistically significant because of the large sample sizes. Certified practices did, however, have a larger share of patients covered by Medicaid and a smaller share covered by Medicare.

Table 3 shows summary statistics describing average $\mathrm{HCH}$ practice systems scores and diabetes care measures by certification status. These unadjusted results indicate that the $\mathrm{HCH}$-uncertified practices had fewer practice systems in place, at least for care coordination and care plan development. The standard deviations for the practice systems scores were much larger than any differences between groups, however, indicating extensive overlap between the certification groups. Uncertified practices also had lower a level of the composite measure of optimal diabetes care, as well as lower levels of statin use and nonsmoking status.

Table 4 allows more specific comparisons of the above differences after adjusting for differences in practice characteristics (medical group size, location, and Federally Qualified Health Center status) and, for care measures, differences in patient characteristics, in a multivariate analysis. This analysis confirmed the differences in overall practice systems, care coordination, and care plans, but access also now differed significantly by certification status; scores were a significant $4.5 \%$ to $9.5 \%$ higher for certified practices vs uncertified practices. Adjusted differences in care measures now were significantly higher for the certified group for all measures except for hypertension control, although the absolute differences were smaller (an absolute $0.1 \%$ to $5.1 \%$ ) than those for systems scores.

\begin{tabular}{|c|c|c|c|c|}
\hline Characteristic & $\begin{array}{l}\text { Certified } \\
\text { Practices }\end{array}$ & $\begin{array}{l}\text { Uncertified } \\
\text { Practices }\end{array}$ & $\begin{array}{c}P \\
\text { Value }^{a}\end{array}$ & Total \\
\hline \multicolumn{5}{|l|}{ Practices } \\
\hline Number & 258 & 136 & $\ldots$ & 394 \\
\hline Ownership, \% & & & .75 & \\
\hline $\begin{array}{l}\text { Large hospital-affiliated } \\
\text { medical group }\end{array}$ & 78.3 & 75.7 & & 77.4 \\
\hline $\begin{array}{l}\text { Medium/small medical } \\
\text { group }\end{array}$ & 18.6 & 19.9 & & 19.0 \\
\hline Single site & 3.1 & 4.4 & & 3.6 \\
\hline $\begin{array}{l}\text { Federally Qualified Health } \\
\text { Center, \% }\end{array}$ & 3.9 & 1.5 & .19 & 3.1 \\
\hline Location, \% & & & $<.001$ & \\
\hline Metropolitan/urban & 76.0 & 49.3 & & 66.8 \\
\hline Large rural town & 6.2 & 15.4 & & 9.4 \\
\hline Small rural town & 7.0 & 5.2 & & 6.4 \\
\hline Isolated rural town & 10.9 & 30.2 & & 17.5 \\
\hline \multicolumn{5}{|l|}{ Patients with diabetes } \\
\hline Number & 158,547 & 58,932 & $\ldots$ & 217,479 \\
\hline Age, mean (SD), y & $\begin{array}{l}58.0 \\
(11.5)\end{array}$ & $\begin{array}{l}59.4 \\
(11.4)\end{array}$ & $<.001$ & $\begin{array}{l}58.4 \\
(11.5)\end{array}$ \\
\hline Female, \% & 46.6 & 45.8 & .46 & 46.3 \\
\hline Insurance, \% & & & $<.001$ & \\
\hline Commercial & 44.6 & 43.9 & & 44.5 \\
\hline Medicaid & 11.0 & 6.5 & & 9.8 \\
\hline Medicare & 36.9 & 43.4 & & 38.7 \\
\hline Dual Medicare-Medicaid & 4.4 & 4.4 & & 4.4 \\
\hline Self-pay/uninsured & 3.0 & 1.8 & & 2.7 \\
\hline $\begin{array}{l}\text { Ischemic vascular disease } \\
\text { prevalence, } \%\end{array}$ & 15.2 & 16.9 & $<.001$ & 15.7 \\
\hline Depression prevalence, $\%$ & 23.9 & 22.7 & $<.001$ & 23.5 \\
\hline \multicolumn{5}{|l|}{$\mathrm{HCH}=$ health care home. } \\
\hline \multicolumn{5}{|c|}{$\begin{array}{l}\text { a Difference in practice characteristics by certification status tested using a Pearson } \chi^{2} \text { test. Dif- } \\
\text { ference in patient characteristics by certification status tested by modeling outcome as a func- } \\
\text { tion of the certification variable, with practice random effects and clustered standard errors to } \\
\text { account for correlation in patient outcomes within practice. }\end{array}$} \\
\hline
\end{tabular}


Finally, we estimated the impact of an increase in practice systems score on the composite diabetes outcome measure, using patient-level logit regression analysis controlling for patient and practice characteristics (available from the corresponding author). As shown in Table 5, a 1-SD increase was significantly $(P<.001)$ associated with a $1.4 \%$ increase in the probability of meeting the composite measure of optimal diabetes care, driven primarily by increases in the hypertension control and hemoglobin $\mathrm{A}_{1 \mathrm{c}}$ control components of that composite.

\section{DISCUSSION}

Our findings document that in a state with rigorous $\mathrm{PCMH} / \mathrm{HCH}$ certification requirements passed by a majority of primary care practices, there were some differences between those that have been certified and those that have not 7 years after certification began. $\mathrm{HCH}$-certified practices were much more likely to be in metropolitan areas and to have a higher proportion of patients covered by Medicaid, but a lower proportion covered by Medicare. Other differences in prac-

\section{Table 3. Comparison of HCH Practice Systems Scores and} Diabetes Care Measures

\begin{tabular}{|c|c|c|c|c|}
\hline Variable & $\begin{array}{l}\text { Certified } \\
\text { Practices }\end{array}$ & $\begin{array}{l}\text { Uncertified } \\
\text { Practices }\end{array}$ & $\begin{array}{c}P \\
\text { Value }^{a}\end{array}$ & Total \\
\hline \multicolumn{5}{|l|}{ Practices } \\
\hline Number & 258 & 136 & $\ldots$ & 394 \\
\hline \multicolumn{5}{|l|}{$\begin{array}{l}\text { Practice systems score, } \\
\text { mean (SD), \%b }\end{array}$} \\
\hline Overall & $79.2(16.2)$ & $74.9(15.0)$ & .01 & $77.7(15.9)$ \\
\hline Access & $75.9(19.8)$ & $72.7(19.3)$ & .13 & $74.8(19.7)$ \\
\hline Registry & $92.3(15.2)$ & $91.3(15.9)$ & .54 & $92.0(15.5)$ \\
\hline Coordination of care & $74.9(20.5)$ & $68.7(23.2)$ & .006 & $72.8(21.7)$ \\
\hline Care plan & $75.4(27.8)$ & $66.6(26.2)$ & .003 & $72.4(27.5)$ \\
\hline Quality improvement & $91.9(18.7)$ & $93.9(14.1)$ & .27 & $92.6(17.3)$ \\
\hline \multicolumn{5}{|l|}{ Patients with diabetes } \\
\hline Number & 158,547 & 58,932 & $\ldots$ & 217,479 \\
\hline \multicolumn{5}{|l|}{ Diabetes care measure, \% } \\
\hline $\begin{array}{l}\text { Composite optimal } \\
\text { diabetes care }\end{array}$ & 46.8 & 43.2 & $<.001$ & 45.8 \\
\hline Aspirin use & 99.6 & 99.5 & .02 & 99.6 \\
\hline Hypertension control & 84.4 & 83.4 & .38 & 84.1 \\
\hline Statin use & 88.5 & 84.7 & $<.001$ & 87.4 \\
\hline Hemoglobin $A_{1 c}$ control & 70.1 & 69.9 & .83 & 70.1 \\
\hline Nonsmoking status & 84.7 & 83.1 & .001 & 84.3 \\
\hline
\end{tabular}

$\mathrm{HCH}=$ health care home.

a Difference in practice characteristics by certification status tested using a 1-way ANOVA test. Difference in patient characteristics by certification status tested by modeling outcome as a function of the certification variable, with practice random effects and clustered standard errors to account for correlation in patient outcomes within practice.

b Percentage of possible total score, where higher values indicate larger percentage of practices having that system in place.

' To be included in the numerator for this measure, a patient must have had met all 5 components. tice patient characteristics by age, sex, and prevalence of ischemic vascular disease or depression are small.

More importantly, when controlling for these differences, certified practices tended to have both more $\mathrm{HCH}$-related practice systems and higher performance on some measures of the quality of diabetes care. The differences between group averages were not large, however, and there was considerable overlap between certified and uncertified practices with no clear boundary distinction between them as groups. Nevertheless, our finding that a higher practice systems score is associated with better diabetes performance measures suggests that practices wishing to improve their care and outcomes for patients with diabetes should consider how to best improve their practice systems, regardless of whether they are certified as medical homes. In another article, we describe additional analyses that identify those specific practice systems significantly associated with better results, both for all practices and for practice subtypes. ${ }^{20}$

Wiley et $\mathrm{a}^{21}$ have been studying the presence of what they call care management processes (similar to what we are calling practice systems) for chronic illness care in practices nationally and have reported that between 2006 and 2013, there were "relatively large increases over time in the overall use of these processes" for all sizes of practices. Similarly, Taliani et a $\mathrm{l}^{22}$ conducted a qualitative study of care management in 25 practices with $\mathrm{PCMH}$ recognition. Interviews with personnel in the practices having the greatest improvement in diabetes performance measures found that they described "more patient-centered care manager duties, better use of the electronic medical record for messaging and patient tracking, and stronger integration of the care manager into the care team," all systems that we measured in this study.

Although our study and the literature suggest that practice systems are associated with better performance, a key question is whether differences between certified and uncertified practices in these attributes are due to the certification process or whether they reflect self-selection as practices with more systems and better outcomes choose to become certified. Our cross-sectional study conducted at a point 7 years after certification began cannot answer that question, but other clues may help.

First, in a study of Minnesota $\mathrm{HCH}$ practices in 2010, we compared similar diabetes performance measures for the first 
of systems and outcomes, our analysis is limited by the cross-sectional nature of our data as well as the focus on a single state and a single chronic disease (diabetes). The practice systems survey is also limited by reliance on completion by a single participant with no objective verification of the presence of the systems being reported. In early tests of a very similar questionnaire, however, we demonstrated that such respondents did a good job of reporting, tending if anything to underreport practice systems more than overreport them. ${ }^{14}$

In conclusion, we have shown some differences in characteristics and practice systems, and in performance measures of diabetes care between practices that are certified as medical homes and those that are not. There also appears to be an association between systems and performance, so practices wanting to improve their care and performance measures should improve the number and function of practice systems, regardless of certification status. Most of the differences are small, however, so it is likely that none of these factors represent magic bullets that can be relied on to achieve large gains in performance over short periods of time. Organizational change is as slow as individual behavior change, but those interested in facilitating improvement need guidance on what changes will be most helpful, and that is the central goal of this ongoing project.

To read or post commentaries in response to this article, see it online at http://www.AnnFamMed.org/content/18/1/66.

Submitted April 16, 2019; submitted, revised, July 1, 2019; accepted July 19, 2019.

Key words: diabetes mellitus; organizational innovation; patient-centered care; primary health care; quality assurance, health care; practicebased research

Funding support: Research reported in this publication was supported by the National Institute of Diabetes, Digestive, and Kidney Diseases of the National Institutes of Health under Award Number R18DK110732.

Disclaimer: The content of this article is solely the responsibility of the authors and does not necessarily represent the official views of the National Institutes of Health.

\section{References}

1. Solberg LI, Asche SE, Fontaine P, Flottemesch TJ, Pawlson LG, Scholle SH. Relationship of clinic medical home scores to quality and patient experience. J Ambul Care Manage. 2011;34(1):57-66.

2. Sia C, Tonniges TF, Osterhus E, Taba S. History of the medical home concept. Pediatrics. 2004;113(5)(Suppl):1473-1478.

3. Grundy P, Hagan KR, Hansen JC, Grumbach K. The multi-stakeholder movement for primary care renewal and reform. Health Aff (Millwood). 2010;29(5):791-798.

4. Jabbarpout Y, DeMarchis E, Bazemore A, Grundy P. The Impact of Primary Care Practice Transformation on Cost, Quality, and Utilization: A Systematic Review of Research Published in 2016. Washington, DC: Patient-Centered Primary Care Collaborative and Robert Graham Center; 2017.
5. Bitton A, Martin C, Landon BE. A nationwide survey of patient centered medical home demonstration projects. J Gen Intern Med. 2010;25(6):584-592.

6. Solberg LI, Van Royen P. The medical home: is it a blind men and elephant tale? Fam Pract. 2009;26(6):425-427.

7. Solberg LI. How can we remodel practices into medical homes without a blueprint or a bank account? J Ambul Care Manage. 2011; 34(1):3-9.

8. Fleming NS, da Graca B, Ogola GO, et al. Costs of Transforming Established Primary Care Practices to Patient-Centered Medical Homes (PCMHs). J Am Board Fam Med. 2017;30(4):460-471.

9. Hahn KA, Gonzalez MM, Etz RS, Crabtree BF. National Committee for Quality Assurance (NCQA) patient-centered medical home $(\mathrm{PCMH})$ recognition is suboptimal even among innovative primary care practices. J Am Board Fam Med. 2014;27(3):312-313.

10. Miller WL. Patient-centered medical home $(\mathrm{PCMH})$ recognition: a time for promoting innovation, not measuring standards. J Am Board Fam Med. 2014;27(3):309-311.

11. Stack E, Kier K. Patient-centered medical homes: standards for approval-part 2: part 2 of 3. Consult Pharm. 2014;29(4):275-278.

12. Solberg LI, Crain AL, Tillema J, Scholle SH, Fontaine P, Whitebird R. Medical home transformation: a gradual process and a continuum of attainment. Ann Fam Med. 2013;11(Suppl 1):S108-S114.

13. Agency for Healthcare Research and Quality. Defining the $\mathrm{PCMH}$. https://www.pcmh.ahrq.gov/page/defining-pcmh. Published 2018. Accessed Apr 26, 2018.

14. Scholle SH, Pawlson LG, Solberg LI, et al. Measuring practice systems for chronic illness care: accuracy of self-reports from clinical personnel. Jt Comm J Qual Patient Saf. 2008;34(7):407-416.

15. Solberg LI, Asche SE, Margolis KL, Whitebird RR, Trangle MA, Wineman AP. Relationship between the presence of practice systems and the quality of care for depression. Am J Med Qual. 2008;23(6): 420-426.

16. Solberg LI, Asche SE, Pawlson LG, Scholle SH, Shih SC. Practice systems are associated with high-quality care for diabetes. Am J Manag Care. 2008;14(2):85-92.

17. Carlin CS, Flottemesch TJ, Solberg LI, Werner AM. System Transformation in Patient-Centered Medical Home (PCMH): variable Impact on Chronically III Patients' Utilization. J Am Board Fam Med. 2016; 29(4):482-495.

18. McCullough JS, Crespin DJ, Abraham JM, Christianson JB, Finch M. Public reporting and the evolution of diabetes quality. Int J Health Econ Manag. 2015;15(1):127-138.

19. United States Census Bureau. About the American Community Survey. https://www.census.gov/programs-surveys/acs/about.html. Accessed Sep 23, 2018.

20. Peterson KA, Carlin C, Solberg LI, Jacobsen R, Kriel T, Eder M. Redesigning primary care to improve diabetes outcomes: the UNITED study. Diabetes Care. In press.

21. Wiley JA, Rittenhouse DR, Shortell SM, et al. Managing chronic illness: physician practices increased the use of care management and medical home processes. Health Aff (Millwood). 2015;34(1):78-86.

22. Taliani CA, Bricker PL, Adelman AM, Cronholm PF, Gabbay RA. Implementing effective care management in the patient-centered medical home. Am J Manag Care. 2013;19(12):957-964.

23. Shippee ND, Finch M, Wholey D. Using Statewide Data on Health Care Quality to Assess the Effect of a Patient-Centered Medical Home Initiative on Quality of Care. Popul Health Manag. 2018;21(2):148-154.

24. Jaen CR, Ferrer RL, Miller WL, et al. Patient outcomes at 26 months in the patient-centered medical home National Demonstration Project. Ann Fam Med. 2010;8(Suppl 1):S57-S67.

25. Wang JJ, Winther $\mathrm{CH}$, Cha J, et al. Patient-centered medical home and quality measurement in small practices. Am J Manag Care. 2014; 20(6):481-489. 